\title{
PATHOGENESIS OF PULLORUM DISEASE (PD) IN CHICKENS BY LOCAL ISOLATE OF Salmonella pullorum IN BANGLADESH
}

\author{
M.G. Haider ${ }^{1 *}$, E.H. Chowdhury, S.M.K. Sharif ${ }^{2}$ and M.M. Hossain \\ Department of Pathology, Faculty of Veterinary Science, BAU, Mymensingh-2202, Bangladesh
}

\begin{abstract}
Pullorum disease is caused by Salmonella enterica subspecies enterica serovar Pullorum. Chickens are the natural host of this pathogen. In the present study experimental pathogenesis was studied. Twenty pullets (Salmonella pullorum seronegative) of Isa Brown breed of 18 weeks and 10 cocks (Salmonella pullorum seronegative) of RIR breed of 26 weeks of age were experimentally infected orally with $2 \times 10^{7}$ (CFU) dose of Salmonella Pullorum organisms and in control group no bacteria was given. Birds were observed for clinical signs, gross pathology, and reisolation of $S$. Pullorum from different organs and blood, histopathological study, detection of antibody levels and detection of $S$. Pullorum by PCR at different time intervals of experimental period. Four hens and one cock were randomly selected and sacrificed on $6 \mathrm{hr}$ before inoculation and $1 \mathrm{wk}, 2,3$ and 4 wks of post infection (PI). Samples were collected for bacteriological, serology and histopathological examinations. Liver, lungs, ovarian follicles and testis were also collected in $50 \%$ buffered- glycerol and preserved in $-80^{\circ} \mathrm{C}$ for PCR. The clinical signs of infected hens were found at $72 \mathrm{hrs}$ of $\mathrm{Pl}$, which continued up to 4 wks. $15.81 \%$ reduction in egg production was observed. The highest mean CFU $\mathrm{ml}^{-1}$ of Salmonella Pullorum from blood was $13.55 \times 10^{3}$ at 1 wk PI and the lowest was $13 \times 10^{2}$ at 4 wk PI. Gross lesions were variable in different birds at different time interval. The highest gross lesion was $93.75 \%$ as swollen and congested spleen and the lowest lesion was $43.75 \%$ as pericarditis and necrotic foci/ nodules in the heart. Microscopically, the liver showed congestion; hepatitis with infiltration of inflammatory cells, and focal necrosis with nodule formation. The antibody titre increased gradually and the highest titer was at 4 wks $\mathrm{PI}$ in hens $(4712 \pm 1851)$ than that of cock $(3059 \pm 903)$. S. Pullorum was
\end{abstract}

\footnotetext{
${ }^{*}$ Corresponding author email: ghaider.bsmrau@gmail.com

${ }^{1}$ Department of Pathobiology, Bangabandhu Sheihk Mujibur Rahman Agricultural University Gazipur-1706, Bangladesh

${ }^{2}$ Avian Influenza Preparedness and Response Project, DLS, Dhaka-1215
}

Received: 22.05.2012 
detected by PCR in all liver and lung samples from 1 wk to 4 wks PI. S. Pullorum was reisolated from male and female reproductive organs after experimental infection. S. Pullorum was detected by PCR at 1 wk to 3 wks PI from testicular tissues. S. Pullorum was also reisolated from $50 \%$ eggs of experimentally infected birds.

Keywords: Chickens, pathogenesis, pullorum disease

\section{INTRODUCTION}

Pullorum disease is one of the major constraints of poultry industries in Bangladesh (Das et al., 2005). Khan et al. (1998) recorded 12\% morbidity and 75\% mortality at the age of 5 wks in broiler breeder replacement pullets of Shaver Red Bro breed at Bangladesh Agricultural University Poultry Farm. They also recorded $100 \%$ morbidity and $75 \%$ mortality in local birds at the age of 8 wks with oral dose of $0.5 \mathrm{ml}$ of $10^{7} \mathrm{CFU}$ of S. Pullorum. A total of 33,204 birds at different groups were investigated for Salmonella infection in Bangladesh. The morbidity and mortality rate due to salmonellosis among the birds were $4.90 \%$ and $1.83 \%$, respectively. The mortality rate was highest $(68.53 \%)$ in the early age groups (0-3 months). It decreased with age and was reduced to $0.25 \%$ in the twelve months and above age group (Khan et al., 1998).

PD causes great economic losses every year in poultry farms and it has also public health significance (Shivaprasad, 1997). The diseases can spread via meat and eggs. A few investigations on natural cases of Salmonella infections have been completed in Bangladesh using the methods of necropsy, histopathology and isolation of bacteria by culture; staining and sugar fermentation tests (Haider et al., 2008). However, no investigations have yet been performed by locally isolated Salmonella Pullorum organisms in respect of pathogenesis, pathology and vertical transmission in chickens. For this reason, the present study was taken for better diagnosis, prevention and control of this economically important pullorum disease in Bangladesh.

\section{MATERIALS AND METHODS}

The proposed research work was conducted at the Department of Pathology, Faculty of Veterinary Science, Bangladesh Agricultural University, Mymensingh during the period from March 2007 to March 2009.

\section{Experimental hens and cocks}

A total of 40 pullets (Salmonella Pullorum seronegative) of Isa Brown breed of 18 wks were purchased from Nourish Hatchery Ltd., Shreepur, Gazipur, Bangladesh and 10 cocks (Salmonella Pullorum seronegative) of RIR breed of 26 weeks old were taken from BAU Poultry farm. The birds were vaccinated against MD, IBD, IB, Fowl Pox and ND obtained from intervet, Holland. The birds were divided into two groups in which one group remained as control. 


\section{Bacterial infection}

25 birds ( 20 hens at the age of 21 wks and 5 cocks at the age of 29 wks) were experimentally infected orally with $2 \times 10^{7}$ (CFU) dose of Salmonella enterica sub. enterica serovar Pullorum (Isolate no. 5) organisms in $0.5 \mathrm{ml}$ broth culture with 0.5 $\mathrm{ml}$ of sterile phosphate buffer saline (PBS), $\mathrm{pH}$ 7.2, using sterile syringe (Roy et al., 2001; Wigley et al., 2005). Control birds were given only $0.5 \mathrm{ml}$ of nutrient broth without bacteria with $0.5 \mathrm{ml}$ of PBS.

\section{Samples collection}

Five birds ( 4 hens and 1 cocks) in each case were randomly selected and sacrificed on 6 hrs before inoculation and 1, 2, 3 and 4 wks of post infection. A total of 25 (20 hens and 5 cocks) birds were used for the control group, and necropsied in similar way along with the infection groups. Different types of samples were collected as described early. Eggs, ova and parts of female reproductive organs were collected for the isolation of organisms (Wigley et al., 2005).

\section{Clinical signs}

Clinical signs of chickens after experimental infection were observed and recorded up to necropsy (Okamura et al., 2000; Wray and Davies, 2001).

Feed consumption was calculated by $=\frac{\text { Total feed supplied }- \text { Amount of residues }}{\text { Total number of birds }}$
Loss of egg production $(\%)$ calculated by $=\frac{\text { Eggs control group }- \text { Eggs in infected group }}{\text { Eggs in control group }} \times 100$

\section{Gross Pathological study}

At necropsy, gross tissue changes were observed and recorded carefully (Roy et al., 2001; Wray et al., 2001).

\section{Reisolation of Salmonella Pullorum from different organs}

Collected samples (crop, liver, lung, heart, duodenum, cecum, kidney, bile and spleen) were weighed and placed in a tube containing $1 \mathrm{ml}$ of sterile phosphate buffered saline (PBS) solution. The colony-forming units of S. Pullorum were counted followed by standard methods (Haider et al., 2008).

\section{Reisolation of Salmonella Pullorum from the blood}

For each bird of each group of 6 hrs before inoculation and 1, 2, 3 and 4 wks of post infection, $1 \mathrm{ml}$ of blood was collected and S. Pullorum was reisolated as previously described (Haider et al., 2008). 


\section{Histopathological study}

The formalin-fixed tissues were trimmed, processed, sectioned and stained as per standard procedure (Haider et al., 2008). Samples of specific lesions from each group were used in histopathological study.

\section{Immunological responses at the onset of egg laying}

Serum samples were collected at the onset of egg production and ELISA test was performed using early described standard procedure (Barrow et al., 1992).

\section{Detection of Salmonella Pullorum in the hens by PCR}

Genomic DNA of S. Pullorum was extracted from liver, lung and follicle tissue samples using DNA extraction kits (Promega Corp. Madison, WI, USA).Extracted DNA amplification was carried out using commercial PCR kits (PCR Master Mixture Kits, GeNei ${ }^{\mathrm{TM}}$, Bangalore, India) in Gene amplification PCR system 9600 Thermocycler (eppendorf, Germany). Amplified products were separated by electrophoreses on $1.5 \%$ agarose gel containing $5 \mu \mathrm{ml}^{-1}$ ethedium bromide with a 100 bp ladder as molecular weight marker (Desai et al., 2005; Olivera et al., 2003).

\section{Statistical analysis}

Significance of different groups was determined by tje application of chisquare or Fisher's exact probability test using SPSS or MSTAT-C computer software program. Repeated measures analysis were performed with the data of mean feed intake and body weight gain of pullet of different groups at different weeks in a Completely Randomized Design (CRD) for significant variation using the SPSS package program version 10.0. Pair wise comparison of means was done by Least Significant Difference (LSD). The differences in the increase or decrease of the ELISA antibody titre of hens and cocks of different groups at different weeks were analyzed for analysis of variance in a Completely Randomized Design (CRD) using an MSTAT-C computer package program. Significant differences between means were identified by Least Significant Differences (LSD).

\section{RESULTS}

\section{Clinical signs}

All hens and cocks were depressed at 1 and 2 wks PI and showed loss of appetite at 1 and 2 wks of PI. Their feed intake dramatically was reduced significantly $(\mathrm{p}<0.01)$ in infected group. The mean body weights of hens and cocks differed significantly $(\mathrm{p}<0.01)$ between infected and control group. Cumulative clinical sings of hens were loss of appetite $60 \%$, depression $60 \%$, diarrhea $20 \%$ and, emaciation $12 \%$ and loss of egg production $15.81 \%$. The mean egg production differed significantly $(\mathrm{p}<0.01$ and $\mathrm{p}<0.05)$ in infected hens. All clinical signs were not found in all birds. The morbidity (clinical signs) was found $90 \%$ in overall $90 \%$ birds were found to be worked for experimental infection group. No mortality was 
found in infected group during study period. Recovery from clinical signs began at 2 wks PI. No clinical signs and mortality were seen in control group.

\section{Gross pathological study}

The haemorrhagic and congested liver and congested, edematous and brown coloured lungs were observed at 1 wk of PI. The gross lesions were reduced gradually at 3 wks of PI. The gross findings were hemorrhage and congestion in $68.75 \%$ liver and necrotic foci in 56.25\% liver; pericarditis and necrotic foci/ nodules in $62.5 \%$ heart; congested, edematous and brown colour in $68.75 \%$ lungs; caseous materials in 81.25\% intestine, semi-solid, cheesy material and button like ulcer in $87.75 \%$ ceca (Figure 1); swelling and congestion in 93.75\% spleen; enlargement in 56.25\% kidney; misshapen discoloured cystic and congestive in $81.75 \%$ ova (Figure 2); and hemorrhage and congestion in $75 \%$ oviducts. The affected ova contained oily and caseous material enclosed in a thickened capsule. These degenerative ovarian follicles were closely attached to the ovary and they were pedunculated and detached from the ovarian mass.

Cocks were infected with $2 \times 10^{7}$ CFU of S. Pullorum at 29 wks of age. Pericarditis, haemorrhagic and congested liver, congested and caseous lungs, and white foci in the testis were observed in cock at 2 wks PI. The size of the infected testes were reduced compared to control cock. The lowest weight of testis was 9.53 gms at 3 wks PI in infected cock. The mean weight of testes reduced significantly $(p<0.05)$ in infected cocks. Gross lesions were variable in different birds at different time interval. The highest percentage of birds showed (93.75\%) in swollen spleen, while the lowest lesion was reported 56.25\% in enlarged kidney in infected hens.

\section{Reisolation of Salmonella Pullorum from different organs of hens}

Reisolation of Salmonella Pullorum from different organs was variable at different time schedule (Table 1). S. Pullorum was reisolated from liver (93.75\%) (Figure3), lungs (100\%), duodenum (100\%), ceca (100\%), and spleen (100\%) at 1 wk to 4 wks PI (Table 1). The S. Pullorum was also reisolated from crop (81.25\%), heart (87.5\%), bile (18.75\%), and kidney (75\%) during the study period. The most frequent reisolated $S$. Pullorum was $64.58 \times 10^{5}$ in liver at $1 \mathrm{wk}$ PI and the less frequent was $14.96 \times 10^{1}$ in crop at 4 wks PI. The details mean CFU/gm of reisolated S. Pullorum at different time intervals are shown in table 1.

\section{Reisolation of Salmonella Pullorum from blood}

The mean CFU/ml of Salmonella Pullorum was reisolated from blood and shown in table 1 . The blood sample of four hens out of four (4/4) at 1 wk and 2 wks PI, three hens out of four (3/4) and one hens out of four (1/4) at 3 wks and 4 wks PI, respectively were positive for $S$. Pullorum. The highest number of reisolated $S$. Pullorum was $13.55 \times 10^{3}$ at $1 \mathrm{wk}$ PI and the lowest number of reisolated S. Pullorum was $13 \times 10^{2}$ at 4 wks PI from blood sample. No S. Pullorum was found in control group. 


\section{Reisolation of $\boldsymbol{S}$. Pullorum from female reproductive organs}

Salmonella Pullorum was reisolated from ovary (100\%) (Figure 4), ovarian follicle (100\%), oviduct (68.75\%), uterus (56.25\%) and vagina (75\%) of female reproductive organs after experimental infection (Table 2). S. Pullorum was not found in control group.

\section{Reisolation of S. Pullorum from different organs of cocks}

Reisolation rate of Salmonella Pullorum from different organs was variable in different time schedules (Table 3). S. Pullorum was reisolated from liver (100\%), lungs (100\%), heart (75\%), cecum (100\%), spleen (100\%), and testes (75\%) at $1 \mathrm{wk}$ to 4 wks PI. Control group was free from S. Pullorum in culture during the study period.

\section{Histopathological study}

The liver showed (81.25\%) congestion, hepatitis, infiltration of inflammatory cells; multifocal necrotic foci with infiltration of histiocytes in (56.25\%) liver parenchyma; nodule formation with the infiltration of heterophils, lymphocytes, macrophages and plasma cells in (12.5\%) liver (Figure 5). $75 \%$ lungs developed pneumonia and bronchopneumonia which were characterized by hemorrhage, infiltration of neutrophils and lymphocytes, heterophils and mononuclear cells in lung alveoli, and lumen and wall of the bronchus. In 62.5\% heart and pericardium, infiltration of heterophils and lymphocytes was found while nodule was formed with infiltration of heterophils, macrophage and lymphocytes in 31.5\% heart of hens (Figure 6). Focal necrosis and infiltration of heterophils and RE cells were found in 93.75\% spleen. The intestinal (81.25\%) and cecal mucosa (87.5\%) exhibited necrosis and infiltration of mononuclear cells in the submucosa. Congestion and infiltration of heterophils and lymphocytes were seen in (56.25\%) kidneys. Ovary (87.5 \%) and oviduct (75\%) showed haemorrhage and congestion with infiltration of macrophages, plasma cells, heterophils and lymphocytes (Figure 7). In males, degeneration and necrosis of spermatogonia and infiltration of inflammatory cells (heterophils, lymphocytes and plasma cells) in the somniferous tubules of testes were (75\%) found (Figures 8). No lesion was found in cocks of control group.

\section{Immune response in hens after experimental infection with S. Pullorum}

Antibody titre (Mean \pm SD) against Salmonella Pullorum was determined in sera collected at different time intervals and the results are shown in table 4 . The antibody titres of infection group increased significantly $(\mathrm{p}<0.01)$ and the values were 1211.82 at 1 wk PI and reached 4712.39 at 4 wks PI. The antibody titres increased slightly in basal level in control group ranging from 151.69 at 1 wk to 171.29 at 4 wks but the values were statistically insignificant.

\section{Immune response in cocks after experimental infection with S. Pullorum}

Antibody titre (Mean \pm SD) against Salmonella Pullorum was determined in sera collected at different time intervals and the results are shown in table 5 . The range of antibody titre in experimental S. Pullorum infected cocks was 508.20 to 
3059.27 at 1 wk PI to 4 wks PI. In control cocks, the antibody titre varied from 202.74 to 172.56 at similar time intervals with infected group, but these values were insignificant. The antibody titres of infection group increased significantly $(p<0.01)$ while the antibody titres decreased gradually in basal level in control group.

\section{Detection of Salmonella Pullorum by PCR}

Salmonella Pullorum was detected by PCR at different time intervals. No $S$. Pullorum was detected by PCR 6 hrs BI and control birds during study period. S. Pullorum was detected from four out of four liver (4/4), lungs (4/4) and ovarian follicle (4/4) from 1 wk to 3 wks PI in experimental group (Figure 9). Three liver (3/4), and four lungs (4/4) and four ovarian follicles (4/4) out of four at 4 wks PI were positive for $S$. Pullorum by PCR.

\section{DISCUSSION}

In the present study, the oral route of experimental inoculation demonstrated that S. Pullorum caused bacteremia and colonized in the liver, lungs, heart, kidney, intestine, spleen, and ceca of chicks to various degrees that corresponded with the findings of Wigley, et al. (2005). Clinical signs appeared in chicks after 12 hrs PI. These were loss of appetite, depression, drossiness, ruffled feather, and diarrhea, labored breathing, loss of body weight, and pest vent. The clinical findings in this study were similar to the natural/experimental findings of other authors (Shivaprasad, 1997; Wary and Davies, 2001). No mortality was found in adult birds in this study, which was similar to the findings of others (Roy et al., 2001; Wary and Davies 2001).Clinical signs of infected hens were limited to slight depression (100\%) and diarrhoea (75\%) that lasted for 3 days after inoculation with the field isolate of Salmonella Enteritidis phage type 4 (Kinde et al., 2000; Okamura et al., 2001).

The gross findings were haemorrhagic and congested liver, necrotic foci in the liver, pericarditis and necrotic foci/ nodules in heart, congested, edematous and brown colour lungs, semi-solid, cheesy material in ceca, unabsorbed and coagulated yolk, swollen and congested spleen and enlarged kidney. In this investigation, the gross findings described above corresponded with slight variation with the findings of other authors (Chauan and Roy, 2007).

In the present study, after experimental infection S. Pullorum was reisolated from different organs at 1 wk PI. But the maximum number of $S$. Pullorum was reisolated from 1 wk to 2 wk PI. From 3 wk PI reisolation of $S$. Pullorum organisms reduced gradually. The findings of the reisolation and identification of Salmonella Pullorum organisms from different organs have also been described by other investigators (Hoop and Pospishil, 1993; Okamura et al., 2000).The highest percentage of reisolation of S. Pullorum from liver (100\%), lungs (100\%), cecum $(100 \%)$ and spleen (100\%) in hen at 7 days PI corresponded with the reisolation of Roy et al, (2001). Wigley et al. (2001) also recovered S. Pullorum after experimental inoculation at 7 days PI from all tissue samples, which did not correspond with the 
findings of present study. The finding of the reisolation from liver, spleen and cecum with infection of S. Pullorum in the present study was similar to the finding with infection S. Enteritidis of Okamura et al, (2001). The findings of reisolation from liver, heart, crop and intestine with the infection of $S$. Enteritidis phage type of Kinde et al., (2000) did not correspond with the findings of present study. Liver and spleen were $100 \%$ positive at $1 \mathrm{wk} \mathrm{PI}$, and $60 \%$ and $80 \%$ at $18 \mathrm{wk} \mathrm{PI}$, and $37.5 \%$ and 12.5 $\%$ at 22 wk PI with the infection of S. Pullorum at 1 wk old male and female commercial brown -egg- laying chickens which agreed with the findings of Wigley et al, (2005). Wigley et al. (2005) also reported that the reisolation rate gradually decreased from 1 wk onwards while the reisolation had been found decreas from 2 wks onwards in the present study. They infected the birds at 0 days old but in the present study birds were infected at 21 wks of age for female and 29 wks of age for male. The findings in the present study, the reisolation of Salmonella Pullorum in blood culture was the highest at 1 wk PI (13.55 X $\left.10^{3} \mathrm{CFU}\right)$ which was similar to the finding of Okamura et al, (2000).

All experimental hens showed histological lesions in different internal organs at 7 days PI. The histological lesions began from $1 \mathrm{wk}$ PI and decreased gradually at 3 wks PI to onward. The highest lesion was found in spleen, followed by lungs and liver in the present study. In this investigation, hepatitis, tyhpilitis, bronchitis and pneumonia were recorded while Roy et al. (2001) also found similar result. In the present study, the histopathological lesions were hepatitis and infiltration of inflammatory cells in liver; multifocal necrotic foci in the liver; nodule formation in the liver; pneumonia and bronchopneumonia; nodule formation in the lungs; focal necrosis and inflammatory cells in the spleen; infiltration of inflammatory cells in the intestine; ulcer in the cecal tonsils; tyhpilitis and infiltration of inflammatory cells in ceca; congestion in the kidneys and infiltration of inflammatory cells in gizzard; congestion and infiltration of inflammatory cells in the ovary; infiltration of inflammatory cells in the oviduct. The above types of histological lesions with mild variation in severity and infiltration of inflammatory cells were supported for Salmonella infection by different investigators (Chauan and Roy, 2007; Haider et al., 2008).

In this investigation, experimental infection by S. Pullorum, the immune response increased gradually from 1wk PI (titre 1211.82) and the highest titre (4712.39) was found at 4 wks PI which was also similar to the findings of Barrow et al. (1992) and was dissimilar to the findings of Hoop and Pospishil (1993). However, other investigators used other Salmonella organisms to determine the immune response by ELISA and RPA test. Their findings were slightly varied with the present findings due to the strain variation, management, age etc. Skov et al. (2002) was found have highest ELISA titre at 3 wks PI with the infection of S. Typhimurium in Chickens. 
All Salmonella strains screened by PCR resulted in visualization of the predicted 457-bp amplified product in ethidium bromide-stained gels (Stone et al., 1994) and in the present study invA gene also visualized and produced 284-bp amplicon. In this investigation, Salmonella Pullorum was detected from tissue (liver, lung and ovarian follicle) samples by PCR with the amplification of invA gene at 12 hrs PI to onwards. Desai et al. (2005) and Olivera et al. (2003) also detected 284-bp amplicon from tissue samples in experimental infected chickens.

In present study in male, their feed intake and body weights were reduced, which was supported by the finding of Shivaprasad (1997). In the present study, pericarditis, haemorrhagic and congested liver, congested and caseous lungs, and white foci in the testis were observed in cock at 2 wks PI and histopathologically, degeneration and necrosis of spermatogonia, and infiltration of heterophils, lymphocytes and plasma cells in the somniferous tubules of testes were (75\%) found. These gross and histpathological lesions corresponded with the findings of Chauan and Roy (2007). In the present study, S. Pullorum was reisolated from $75 \%$ testes of cocks but Wigley et al. (2005) could not reisolate S. Pullorum in the testes of male birds.

\section{CONCLUSIONS}

In this study, it is clear that after oral route of infection with infective dose of S. Pullorum, the bacteria invades digestive epithelia and ultimately enters into blood called bacteremia. From blood, bacteria are seeded into cells and tissues of different organs such as liver, lung, spleen, kidney, different parts of reproductive tracts of hens and testes of male and other tissues producing pathological lesions. It is also confirmed that the bacteria invade ovary and egg follicles, and this infection persists in ovary and egg follicles and transmits into laid eggs then to hatched chicks. No chronic lesion especially arthritis was recorded in this experiment. In this study pathogenesis and pathology are known in poultry birds of different age groups. In future for the control of Salmonella infections in poultry, vaccine production and sequencing of vaccine candidate in association with phylogenetic analysis of circulating Salmonella organisms should be performed in Bangladesh.

\section{REFERENCES}

Barrow, P. A., Berchieri , A. Jr. and Al-Haddad O. 1992. Serological response of chickens to infection with Salmonella Gallinarum-Salmonella Pullorum detected by enzymelinked immunosorbent assay. Avian Disease, 6: 227-236

Chauhan, H.V.S. and Roy, S. 2007. Poultry Diseases, Diagnosis and Treatment. $3^{\text {rd }}$ edn. New Age International (P) Limited Publishers. New Delhi, India

Das, P.M., Rajib, D.M.M., Noor, M. and Islam, M. R. 2005. Retrospective analysis on the proportional incidence of poultry diseases in greater Mymensingh district of Bangladesh. In Proceeding of $4^{\text {th }}$ International Poultry Show and Seminar, Organized by World's Poultry Science Association, Bangladesh Branch, on February 28 to March 2, Dhaka, Bangladesh 
Desai, A.R., Shah, D.H., Shringi, S., Mi-Jin Lee, Ying- Hua Li, Mae- Rim Cho, Jin-Ho Park, Seong-akug Eo, John-Hwa Lee and Joon-Seok Chae. 2005. An Allele-Specific PCR Assay for the Rapid and Serotype- Specific Detection of Salmonella Pullorum. Avian Disease, 49: 558-561

Haider, M.G., Chowdhury, E.H., Khan, M.A.H.N.A., Hossain, M.T., Rahman, M.S., Song, H.J. and Hossain, M.M. 2008. Experimental pathogenesis of pullorum disease with local isolate of Salmonella enterica serovar. enterica subspecies Pullorum in pullets in Bangladesh. Korean Journal of Poultry Science, 35 (4): 341-350

Hoop, R.K. and Pospishil, A.1993. Bacteriological, serological, histological and immunological findings in laying hens with naturally acquired Salmonella Enteritidis phage type 4 infections. The Veterinary Record, 139:391-393

Khan, M.A.H.N.A., Bari, A.S.M., Islam, M.R., Das, P.M. and Ali, MY. 1998. Pullorum disease in semi mature chickens and its experimental pathology. Bangladesh Veterinary Journal, 32: 124-128

Kinde, H., Shivaprasad, H.L., Daft, B.M., Read, D.H., Ardans, A., Breitmeyer, R., Rajashekara, G., Nagaraja, K.V. and Garder, I.A. 2000. Pathologic and Bacteriologic Findings in 27-week- old Commercial Laying Hens Experimentally Infected with Salmonella enteritidis, Phage Type 4. Avian Disease, 44: 239-248

Okamura, M., Kamijima, Y., Miyamoto, T., Tani, H., Sasai, K. and Baba, E. 2000. Differences Among Six Salmonella Serovars in Abilities to Colonize Reproductive Organs and to Contaminate Eggs in Laying Hens. Avian Diseases, 45: 61-69

Olivera, S.D., Roclenbuisch, C.R., Ce,M.C., Rocha, S.L.S. and Canal, C.W. 2003. Evaluation of selective and non-selective enrichment PCR procedures for Salmonella detection. Letters in Applied Microbiology, 36: 217-221

Roy, H., Dhillion, A.S., Shivaprasad H.L., Schaberg D.M., Bandli D. and Johnson S. 2001. Pathogenicity of Different Serogroups of Avain salmonellae in Specific- PathogenFree Chickens. Avian Disease, 45: 922-937

Shivoprasad, H.L. 1997. Pullorum disease Fowl typhoid. In Calnek, W.B. (ed.), Diseases in Poultry. Iowa State University Press, Iowa State, USA

Skov, M.N., Feld, N.C., Carstensen, B. and Madsen, M. 2002. The serological response to Salmonella Enteritidis and Salmonella typhimurium in experimentally infected chickens, followed by an indirect lipopolysaccharide enzyme immunosorbent assay and bacteriologic examinations through a one -year period. Avian Disease, 46:265-273

Solano, C., Galindo, J., Sesna, B., Aluarrez, M., Solsona, M.J. and Ganazo, C.N. 2000. Enzyme linked immunosorbent assay with a Salmonella enteritidis gene for differentiating infected from vaccinated poultry. The Veterinary Record, 31: 491-497

Stone, G.G., Oberst, R.D., Hays, M.P., McVey, S. and Chengappa, M.M. 1994. Detection of Salmonella serovars from clinical samples by enrichment broth cultivation-PCR procedure. Journal of Clinical Microbiology, 32: 1742-1749

Wary, C. and Davies, R.H. 2001. Pullorum disease. In Jordan, F., Pattison, M., Alexander, D. and Faragher, T. (eds.), Poultry Diseases. S.B. Saunders, Philadelphia, USA

Wigley, P., Hulme, S.D., Powers, C., Beal, R.K., Berchierim, Jr.A., Smith, A. and Barrow, P. 2005. Infection of the Reproductive Tract and Eggs with Salmonella enterica Serovar Pullorum in the Chicken is Associated with Suppression of Cellular Immunity at Sexual Maturity. Infection and Immunity, 73: 2986-2990 
Table 1: Mean CFU/gm of isolated and identified of Salmonella Pullorum from different organs of experimentally infected hens

\begin{tabular}{lllll|l|l}
\hline \multicolumn{1}{c}{ Organs } & \multicolumn{1}{c}{ BI 6 hr } & \multicolumn{1}{c}{ PI 1 wh } & \multicolumn{1}{r}{ PI 2 wk } & \multicolumn{1}{r}{ PI 3 wk } & \multicolumn{1}{r}{ PI 4 wk } \\
\hline 1. Crop & 00 & $58.72 \times 10^{4}$ & $25.81 \times 10^{3}$ & $25.68 \times 10^{2}$ & $14.96 \times 10^{1}$ \\
& $(0 / 4)$ & $(4 / 4)$ & $(4 / 4)$ & $(3 / 4)$ & $(2 / 4)$ \\
2. Liver & 00 & $64.58 \times 10^{5}$ & $65.79 \times 10^{4}$ & $55.98 \times 10^{3}$ & $44.28 \times 10^{3}$ \\
& $(0 / 4)$ & $(4 / 4)$ & $(4 / 4)$ & $(4 / 4)$ & $(3 / 4)$ \\
3. Heart & 00 & $21.34 \times 10^{3}$ & $40.16 \times 10^{3}$ & $48.66 \times 10^{2}$ & $14.71 \times 10^{2}$ \\
& $(0 / 4)$ & $(4 / 4)$ & $(4 / 4)$ & $(3 / 4)$ & $(3 / 4)$ \\
4. Lungs & 00 & $44.85 \times 10^{4}$ & $39.02 .2 \times 10^{4}$ & $66.95 \times 10^{3}$ & $24.26 \times 10^{2}$ \\
& $(0 / 4)$ & $(4 / 4)$ & $(4 / 4)$ & $(4 / 4)$ & $(4 / 4)$ \\
5. Duodenum & 00 & $20.98 \times 10^{5}$ & $47.51 \times 10^{4}$ & $36.54 \times 10^{4}$ & $43.56 \times 10^{3}$ \\
& $(0 / 4)$ & $(4 / 4)$ & $(4 / 4)$ & $(4 / 4)$ & $(4 / 4)$ \\
6. Cecum & 00 & $81.11 \times 10^{5}$ & $73.93 \times 10^{5}$ & $64.47 \times 10^{4}$ & $80.77 \times 10^{3}$ \\
& $(0 / 4)$ & $(4 / 4)$ & $(4 / 4)$ & $(4 / 4)$ & $(4 / 4)$ \\
7. Bile & 00 & $47.88 \times 10^{3}$ & $14.29 \times 10^{3}$ & 00 & 00 \\
& $(0 / 4)$ & $(2 / 4)$ & $(1 / 4)$ & $(0 / 4)$ & $(0 / 4)$ \\
8. Kidney & 00 & $39.72 \times 10^{3}$ & $13.58 \times 10^{3}$ & $18.84 \times 10^{2}$ & $19.26 \times 10^{1}$ \\
& $(0 / 4)$ & $(4 / 4)$ & $(4 / 4)$ & $(2 / 4)$ & $(2 / 4)$ \\
9. Spleen & 00 & $89.25 \times 10^{5}$ & $93.34 \times 10^{5}$ & $62.21 \times 10^{3}$ & $51.25 \times 10^{3}$ \\
& $(0 / 4)$ & $(4 / 4)$ & $(4 / 4)$ & $(4 / 4)$ & $(4 / 4)$ \\
10. Blood & 00 & $13.55 \times 10^{3}$ & $8.43 \times 10^{3}$ & $33.76 \times 10^{2}$ & $13 \times 10^{2}$ \\
& $(0 / 4)$ & $(4 / 4)$ & $(4 / 4)$ & $(3 / 4)$ & $(1 / 4)$ \\
\hline
\end{tabular}

Note: Percentage calculated from 1 wk PI to 4 wks PI.

Table 2: Mean CFU/gm of isolated and identified Salmonella Pullorum from female reproductive organs in experimentally infected hens

\begin{tabular}{l|l|l|l|l|l|l}
\hline \multicolumn{1}{c|}{ Organs } & BI 6 hr & PI 1 wk & PI 2 wk & PI 3 wk & PI 4 wk & $\begin{array}{c}\text { Total } \\
\mathbf{( \% )}\end{array}$ \\
\hline 1.Ovary & 00 & $41.05 \times 10^{5}$ & $64.6 \times 10^{4}$ & $33.05 \times 10^{3}$ & $40.93 \times 10^{4}$ & 100 \\
& $(0 / 4)$ & $(4 / 4)$ & $(4 / 4)$ & $(4 / 4)$ & $(4 / 4)$ & \\
2. Ovarian & 00 & $67.75 \times 10^{4}$ & $47.61 \times 10^{4}$ & $31.67 \times 10^{3}$ & $49.5 \times 10^{3}$ & 100 \\
follicle & $(0 / 4)$ & $(4 / 4)$ & $(4 / 4)$ & $(4 / 4)$ & $(4 / 4)$ & \\
3. Oviduct & 00 & $39.65 \times 10^{4}$ & $25.17 \times 10^{3}$ & $40.67 \times 10^{3}$ & $27.54 \times 10^{3}$ & 68.75 \\
& $(0 / 4)$ & $(4 / 4)$ & $(3 / 4)$ & $(2 / 4)$ & $(2 / 4)$ & \\
4. Uterus & 00 & $40.11 \times 10^{5}$ & $14.36 \times 10^{3}$ & $19.16 \times 10^{3}$ & $30.81 \times 10^{3}$ & 56.25 \\
& $(0 / 4)$ & $(3 / 4)$ & $(3 / 4)$ & $(2 / 4)$ & $(1 / 4)$ & \\
5. Vagina & 00 & $51.15 \times 10^{3}$ & $07.2 \times 10^{3}$ & $43.12 \times 10^{3}$ & $13.13 \times 10^{3}$ & 75 \\
& $(0 / 4)$ & $(4 / 4)$ & $(4 / 4)$ & $(3 / 4)$ & $(1 / 4)$ & \\
\hline
\end{tabular}

Note: Percentage calculated from 1 wk PI to 4 wks PI 
Table 3: CFU/gm of isolated and identified Salmonella Pullorum from different organs of cocks after experimental infection

\begin{tabular}{rl|l|l|l|l|l}
\hline Organs & BI $\mathbf{6} \mathbf{~ h r}$ & $\mathbf{P I} \mathbf{1}$ wk & PI $\mathbf{2}$ wk & PI 3 wk & PI 4 wk & $\begin{array}{c}\text { Total } \\
\mathbf{( \% )}\end{array}$ \\
\hline 1. Liver & 00 & $69.83 \times 10^{3}$ & $158.62 \times 10^{3}$ & $37.05 \times 10^{3}$ & $40.93 \times 10^{2}$ & 100 \\
& $(0 / 1)$ & $(1 / 1)$ & $(1 / 1)$ & $(1 / 1)$ & $(1 / 1)$ & \\
2. Lung & 00 & $60.89 \times 10^{3}$ & $86.90 \times 10^{3}$ & $31.67 \times 10^{3}$ & $49.5 \times 10^{2}$ & 100 \\
& $(0 / 1)$ & $(1 / 1)$ & $(1 / 1)$ & $(1 / 1)$ & $(1 / 1)$ & \\
3. Heart & 00 & $12.24 \times 10^{3}$ & $23.31 \times 10^{3}$ & $41.67 \times 10^{2}$ & 00 & 75 \\
& $(0 / 1)$ & $(1 / 1)$ & $(1 / 1)$ & $(1 / 1)$ & $(0 / 1)$ & \\
4. Spleen & 00 & $105.41 \times 10^{3}$ & $163.36 \times 10^{3}$ & $89.16 \times 10^{3}$ & $30.81 \times 10^{2}$ & 100 \\
& $(0 / 1)$ & $(1 / 1)$ & $(1 / 1)$ & $(1 / 1)$ & $(1 / 1)$ & \\
5. Cecum & 00 & $236.88 \times 10^{3}$ & $118.68 \times 10^{3}$ & $103.12 \times 10^{3}$ & $83.13 \times 10^{3}$ & 100 \\
& $(0 / 1)$ & $(1 / 1)$ & $(1 / 1)$ & $(1 / 1)$ & $(1 / 1)$ & \\
6. Testis & 00 & $35 \times 10^{2}$ & $16.4 \times 10^{3}$ & $19.32 \times 10^{2}$ & 00 & 75 \\
& $(0 / 1)$ & $(1 / 1)$ & $(1 / 1)$ & $(1 / 1)$ & $(0 / 1)$ & \\
\hline
\end{tabular}

Note: Percentage calculated from 1 wk PI to 4 wks PI

Table 4: Antibody titre in hens infected with Salmonella Pullorum detected by indirect ELISA

\begin{tabular}{cccc}
\hline Time schedule of PI & Infection group (Mean \pm SD) & Control group (Mean \pm SD) \\
\hline BI 6 hr & $137.37 \pm 103.66^{*}$ & $138.85 \pm 72.34$ \\
PI 1 wk & $1211.82 \pm 585.07^{*}$ & $151.69 \pm 162.54$ \\
PI 2 wk & $3189.90 \pm 1383.26^{*}$ & $154.24 \pm 129.93$ \\
PI 3 wk & $4312.58 \pm 1476.23^{*}$ & $155.26 \pm 172.18$ \\
PI 4 wk & $4712.39 \pm 1851.94^{*}$ & $171.29 \pm 169.68$ \\
\hline
\end{tabular}

*The mean difference is significant at $\mathrm{p}<0.01$ 
Table 5: Antibody titre in cocks infected with Salmonella Pullorum detected by indirect ELISA

\begin{tabular}{l|l|l}
\hline \multicolumn{1}{c}{ Time schedule of PI } & \multicolumn{1}{c}{ Infection group (Mean \pm SD) } & Control group (Mean \pm SD) \\
\hline BI 6 hr & $182.24 \pm 56.54^{*}$ & $192.05 \pm 38.62$ \\
PI 1 wk & $508.20 \pm 98.77^{*}$ & $202.74 \pm 45.75$ \\
PI 2 wk & $1167.61 \pm 162.39^{*}$ & $193.87 \pm 143.72$ \\
PI 3 wk & $2114.94 \pm 612.03^{*}$ & $189.99 \pm 51.63$ \\
PI 4 wk & $3059.27 \pm 903.40^{*}$ & $172.56 \pm 200.45$ \\
\hline
\end{tabular}

*The mean difference is significant at $\mathrm{p}<0.01$

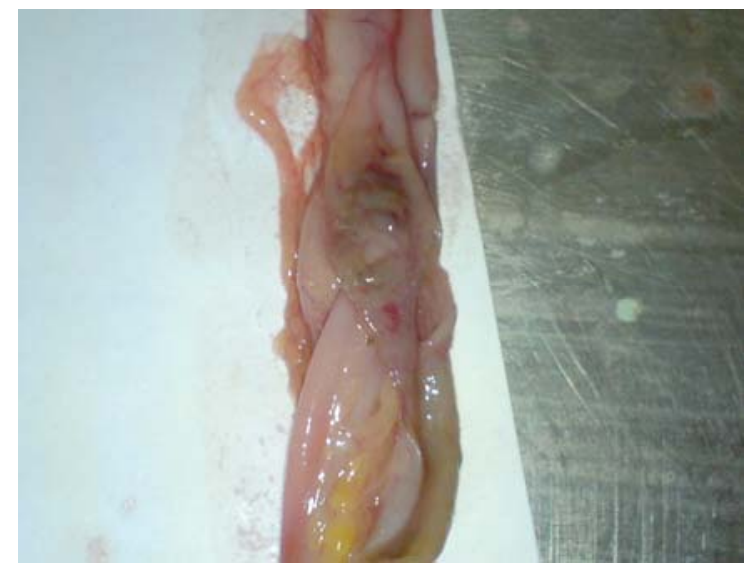

Figure 1: Semi-solid, cheesy material in ceca and button like ulcer at 3 wks PI with experimental infection of $S$. Pullorum.

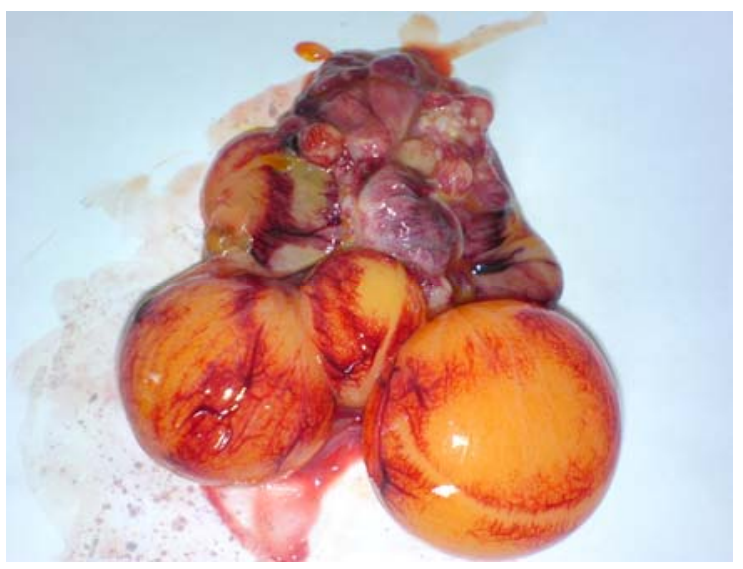

Figure 2: Misshapen, discoloured, cystic and congested ova at 2 wks PI with experimental infection of $S$. Pullorum. 


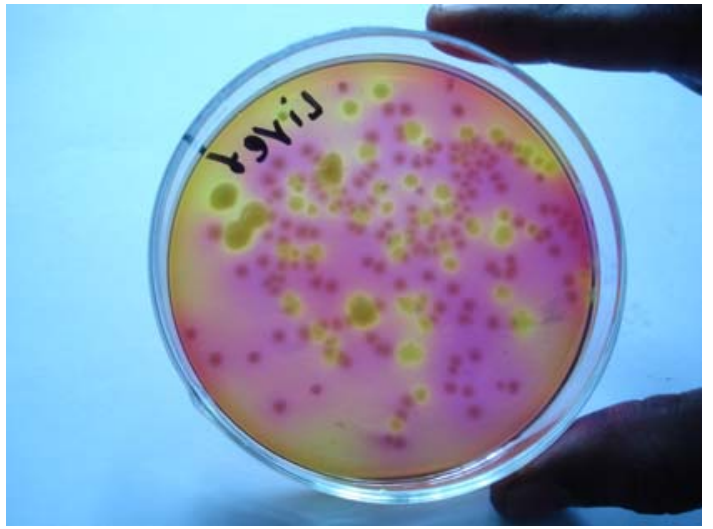

Figure 3: Experimentally infected with $S$. Pullorum at $1 \mathrm{wk}$ PI showing 76 CFU of $S$. Pullorum/gm of tissue of liver at $10^{5}$ dilution.

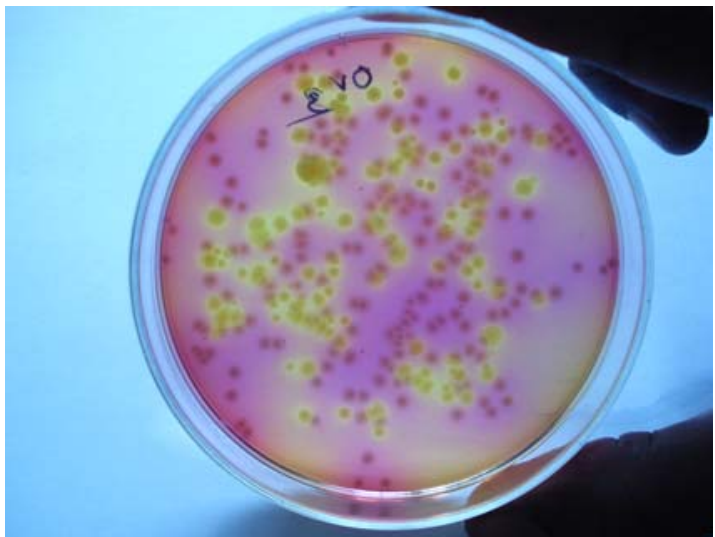

Figure 4: Experimentally infected with $S$. Pullorum at $1 \mathrm{wk}$ PI showing $86 \mathrm{CFU}$ of $S$. Pullorum/gm of tissue of ovary at $10^{5}$ dilution

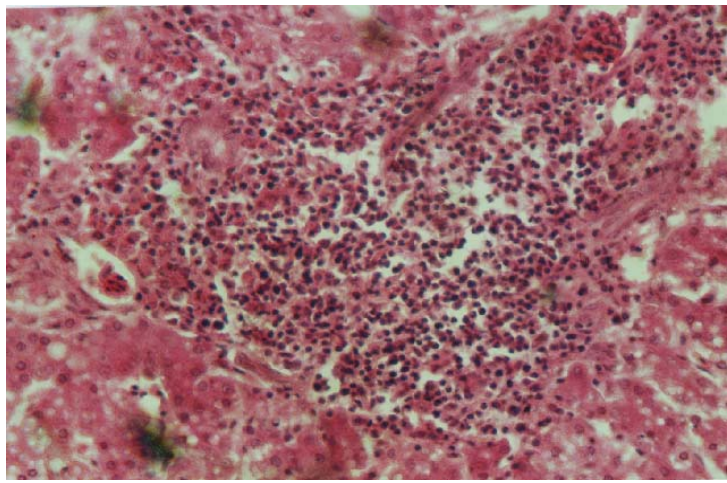

Figure 5: Nodule formation with the infiltration of heterophils, lymphocytes, macrophages and plasma cells in liver in experimental PD in hens at 3 wks PI (H\&E, X 333). 


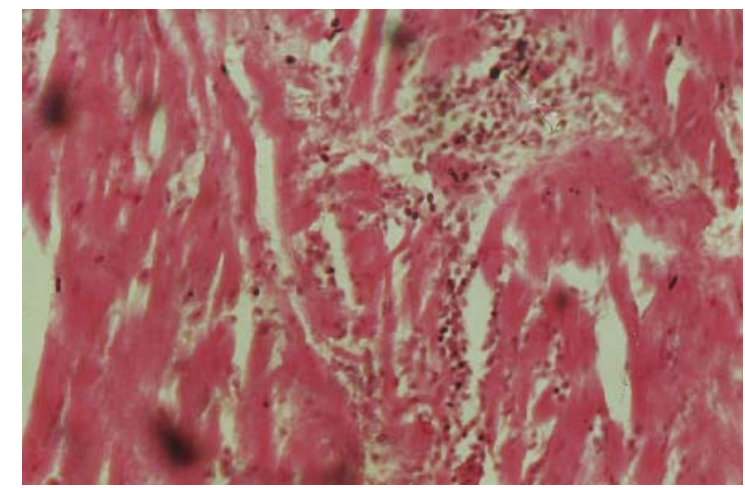

Figure 6: Nodule is formed with infiltration of heterophils macrophage and lymphocytes in heart in experimental PD in hens at 2 wks PI (H\&E, X 333).

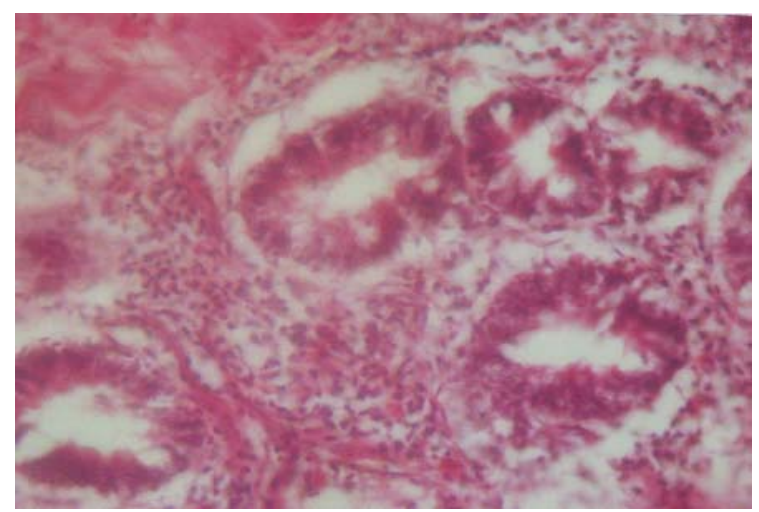

Figure 7: Infiltration of macrophages, heterophils and lymphocytes in the uterus and necrosis in the epithelial cells of the gland in experimental PD in hens at 2 wks PI (H\&E, X 333).

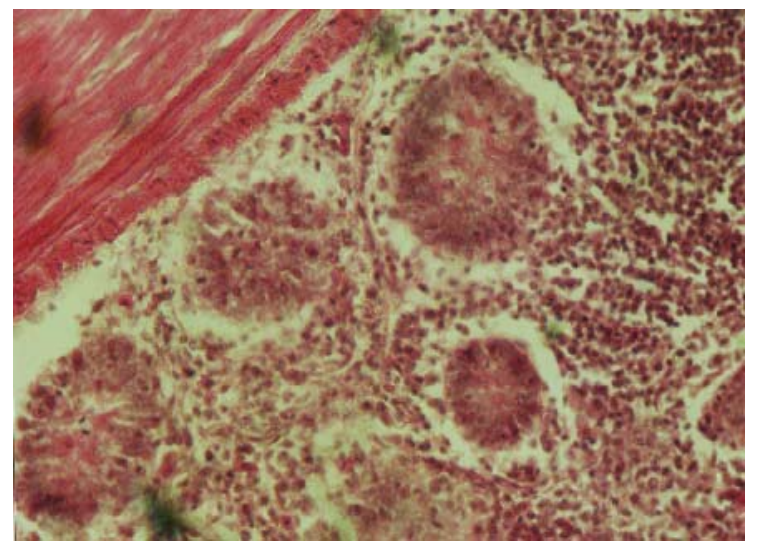

Figure 8: Degeneration and necrosis of spermatogonia and infiltration of heterophils, lymphocytes and plasma cells are found in the somniferous tubules of testes in experimental PD in cock at 3 wks PI (H\&E, X 83). 


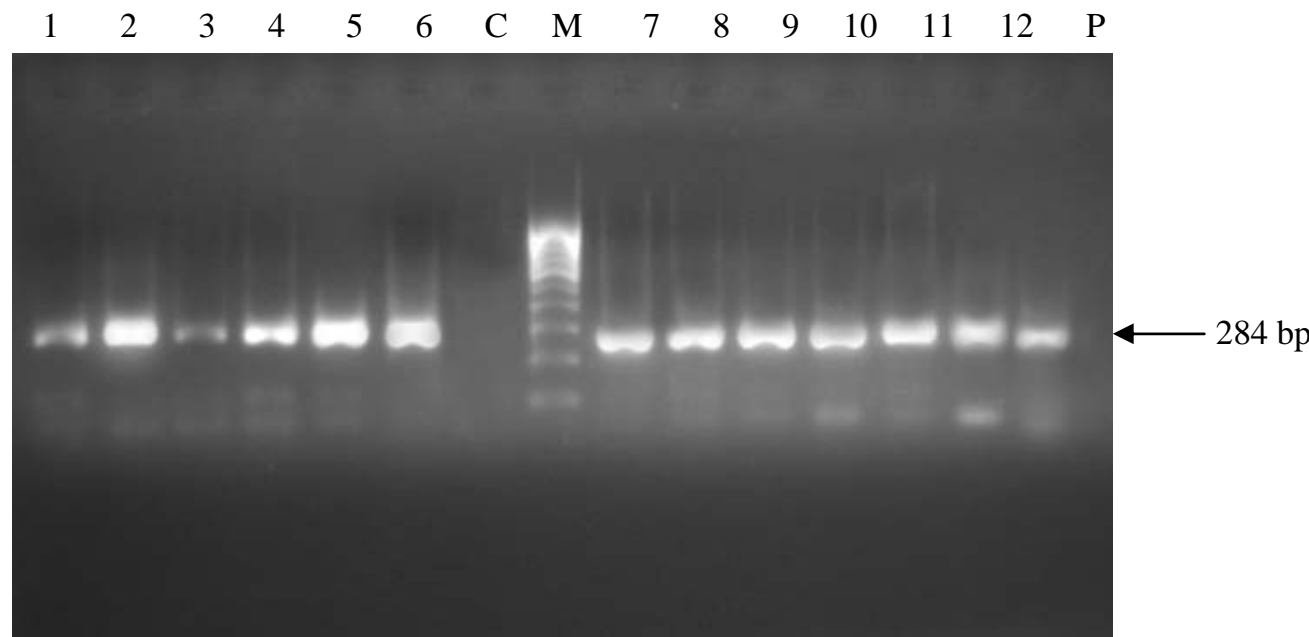

Figure 9: Electrophoresis for Salmonella Pullorum at 1wk of PI on 1.5\% agarose gel showing band from lane 1 to 4 liver, from lane 5 to 8 lungs and from lane 9 to 12 ovarian follicle samples, lane p showing the 284-bp PCR products as a positive control and lane C showing no band as a negative control after amplification with the primer 139 (F) and 141 (R) targeting the gene invA for Salmonella Pullorum and lane M showing DNA molecular mass marker (100-bp ladder). 